\title{
Hackathons, entrepreneurship and the passionate making of smart cities
}

\author{
Sung-YuehPerng, Rob Kitchin and Darach Mac Donncha \\ National Institute for Regional and Spatial Analysis, Maynooth University, Ireland \\ sung-yueh.perng@nuim.ie, rob.kitchin@nuim.ie and darach.macdonncha@nuim.ie

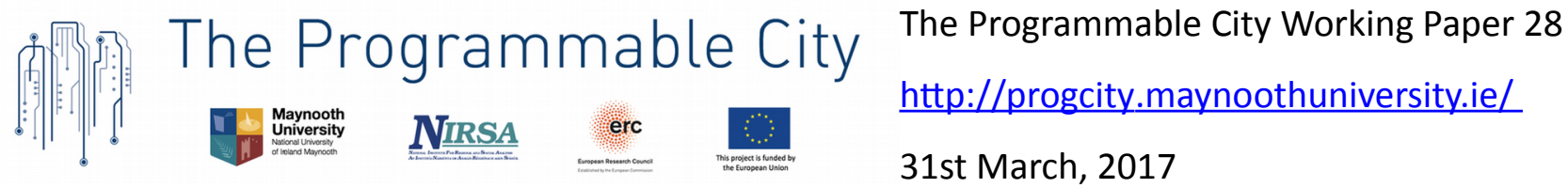

\begin{abstract}
Hackathons - quick prototyping events for commercial purposes - have become an important means to foster innovation, entrepreneurship and the start-up economy in smart cities. Smart and entrepreneurial cities have been critiqued with respect to the neoliberalization of governance and statecraft. We consider the passions, inventions and imitations in the assemblage of practices - alongside neoliberalizing and capitalist operations - that shape the economy and governance of smart cities. The paper examines hackathons as tech events that extend the passions for digital innovation and entrepreneurship and act as sites of social learning for the development of smart urbanism. We argue that passionate and imitative practices energize the desire and belief in entrepreneurial life and technocratic governance, and also engender precarious, ambiguous and uncertain future for participants and prototypes.
\end{abstract}

Keywords: innovation, entrepreneurial life, imitations, passions, smart city, start-up economy 


\section{Introduction}

The first hackathon was held in 1999 as an invitation-only event for programmers with proven skills to gather and write software code to improve Internet security (Open BSD, n.d.). They are now organized regularly as 'tech events' to foster innovation, entrepreneurship and indigenous and global economies. Hackathons usually span a weekend, featuring 'prototyping' and 'innovation by challenge' where teams of coders, makers, domain experts, entrepreneurs and other interested parties work together to produce prototype solutions to a set of problems, or 'challenges'. The themes of hackathons are diverse, including those designed to address social or environmental challenges, and the events can be organized by community groups, charities, local government, and nongovernmental organisations.

We focus our attention on commercially sponsored hackathons because they encourage and enable entrepreneurial economies and cities in the age of 'smart urbanism' (Kitchin, 2015; Marvin et al., 2016). Currently, the majority of hackathons are sponsored by large multinational IT corporations (such as IBM or Intel), start-up companies, and municipalities or government agencies, with a remit of improving urban services and economic growth. Depending on the financial and organisational resources of the organizers, hackathons can take place in a single city, multiple locations or simultaneously across the globe. At the end of the events, a judging panel announces winning prototypes based on how well they addressed the proposed challenges and their potential to be launched as a marketable product. Being selected as the winner in a hackathon can be rewarded with a cash prize and/or enrolment into incubator and accelerator programmes. There is often prestige accompanying the enrolment because it provides access to wider business networks and investment opportunities from venture capital or multinational corporations. Accordingly, successful transition from hackathon ideas to start-up companies becomes an important strategy to grow digital and indigenous economies in the smart city.

Hackathons can be contextualised within an overarching neoliberal drive to redesign and marketize urban governance. City administrations are adopting new forms of performance-based managerialism and working more closely with business, either through public-private partnerships, or contracting out or privatising services to increase efficiency and lower costs (Kitchin, 2015; Marvin, Luque-Ayala, \& McFarlane, 2016; Vanolo, 2013). 
Hackathons further facilitate that process by translating 'knowledge, skills and creativity ... into valuable processes, products and services' when focusing on ideas and innovations for developing an 'enterprise economy' (Government of Ireland, 2008, p. 7). In part, this reconfiguring of urban governance is seen as necessary to support and enhance the economic competitiveness of cities and regions, continuing a strategy leveraged earlier in the process of seeking to create 'entrepreneurial cities' (Jessop, 1997). In this context, hackathons can be seen as maintaining business-led urban development and the transition from managerial to entrepreneurial urban governance, along with other initiatives including living labs, urban testbeds, innovation or smart districts, industrial parks by local governments in partnership with multinational corporations, and local stakeholders in cities around the world (Datta, 2015; Evans \& Karvonen, 2014; Heaphy \& Pétercsák, 2016; Hollands, 2008; Shelton, Zook, \& Wiig, 2015). Accordingly, regardless of the focus, aim, organizer or sponsor, hackathons enculturate instrumental rationality in the format of a weekend propaganda camp where societal issues are reduced to technological fixes and can, and should be, addressed by private enterprise and citizens, rather than by the state.

Reflecting on this ongoing transition, existing debates on the entrepreneurial development of cities centre around the variations of 'statecraft' that facilitate such a transition (Lauermann, 2016). Entrepreneurial city governments can pursue 'a direct, interventionist role' in the formulation of social, spatial and economic policies, amidst the 'recognition of the limits of privatism in the development and delivery of public policy' (Raco, 2012, p. 163). The development of urban laboratories through public-private partnerships becomes another strategy that entrepreneurial city advocates adopt to cocreate the city's economic, social and environmental future (Karvonen \& van Heur, 2014). In experimenting with different technologies and policies to restructure local governments it is argued that a greater diversity of stakeholders become involved in urban governance and more initiatives and interventions can be trialled. For instance, civil society groups can join local governments and international institutions (e.g. consultancy organisations) to mobilize and shape policies for 'co-produced entrepreneurialism' (McFarlane, 2012). In integrating smart city initiatives into municipalities and existing structures of local governance, partnerships that cut across public, private and civic domains are established and connect local and extra-territorial networks of key actors, technologies and organisations for promoting the technological acumen in the cities' economies and citizenship (Evans \& Karvonen, 2014; Shelton et al., 2015). 
Similarly, policies are mobilized to establish and integrate 'smart' economic and social programmes, and are also replicated elsewhere through the promotion and business agenda of a broad 'advocacy coalition' (Sabatier \& Jenkins-Smith, 1993) of lobby and business groups (e.g., Smart City Council, TM Forum), governmental (e.g., the EU's European Innovation Partnership in Smart Cities and Communities) and non-governmental (e.g., Eurocities, Covenant of Mayors) stakeholders, and academics (e.g., smart city research institutes), or through municipalities replicating the initiatives of other competing cities and urban regions (Datta, 2015; Kitchin, Coletta, Evans, Heaphy, \& Mac Donncha, 2017; Wiig, 2015). As such, the strategies developed in one urban context can circulate and become implicated in the 'interconnected trajectories of socio-spatial change' in different urban districts (Hart in Ward, 2006, p. 56), forming complex patterns of concurrent competition and cooperation among smart cities. Accordingly, these moorings and strategies for the development of smart cities can be understood as the latest incarnation of the entrepreneurial city (in much the same way as the creative city was a form of entrepreneurial urbanism).

However, the emergence of entrepreneurial cities and smart urbanism would not be possible without the passionate participation of individuals, specific government agencies and private organisations, and the demonstrable progress of entrepreneurial pursuits and their ideas, whether through hackathons or other similar events or initiatives. Therefore, what is missing in the current literature is a way of considering how such passionate socioeconomic practices lead to what can be recognised as start-up economy and smart urbanism. Relatedly, what is also overlooked include the socioeconomic practices that energize the desires, believes and pursuits for entrepreneurial life and the material and economic arrangements for neoliberalising and technocratic practices and governance. This paper adds to the understanding of smart urbanism and entrepreneurial life by synthesizing Tarde's work on passions and imitations and existing literature on capitalist, neoliberal and exploitative operations that re-structure work, societies and cities. We examine hackathons as an example to illustrate the passionate participation in establishing entrepreneurial life and also attend to the consequences of the passionate and imitative socioeconomic practices in the engineering of smart cities. Following Tarde, we do not seek to examine societal or historic metamorphoses 'from afar, roughly, and from the outside', although recognising their lingering effects, and instead venture 'up close, in small numbers, and from the inside' (Latour \& Lépinay, 2009, p. 28; original emphasis). We thus approach 
smart cities and their neoliberal logic not as a 'fundamental continuity in historic metamorphoses' (Tarde, 1903, p. 2), but rather by attending to the continuous, inventive and imitative practices that sustain and renew particular desires, beliefs and ideas about the cities. Drawing from 40 interviews on hackathon and civic hacking practices in Dublin, our analysis here is based on 24 interviews with attendees of corporately sponsored hackathons (aged from 20s to 40s; 19 male and 5 female; mostly programmers), including four with organizers (all male). We also attended four hackathons as researchers to observe their unfolding and a further two as participants, and participating in two winning team meetings with a city council to explore future potential development of a winning prototype.

\section{Passions and imitations in smart cities}

Creativity, innovation and urban transformation have largely been explained through the lens of institutionalist economic growth or the fostering of a creative and knowledge economy (David \& Foray, 2002; Gibson \& Klocker, 2005; Mansfield, 1968; Scott, 2006; Wyly, 2013). However, understanding such change through Gabriel Tarde's work, particularly The Laws of Imitation (1903) and Economic Psychology (2007), requires an attention towards imitation of all kinds - 'spontaneous and unconscious or artificial and deliberate' - and actors that enable the propagation of new inventions or ideas, which are subsequently 'transmitted from generation to generation through direct instruction' (Tarde, 1903, pp. 24). ${ }^{1}$ Also, instead of attributing change to individual ingenuity, Tarde contends that inventions 'are composed of prior imitations' and situated in a series of incremental differences (Tarde, 1903, p. 45). As Barry and Thrift (2007) further explain, inventions arise from unanticipated disruption to routinely exercised and well-established ideas and practices. The alternations performed to resume effectiveness are thus the basis of invention and subsequent imitation.

The effects of individual inventions and their subsequent imitations accumulate to form recognisable patterns and, in our case, shape smart cities. In Tarde's term, the effects manifest as 'radiations of imitations', or 'imitative rays' for Latour and Lépinay (2009, p.

\footnotetext{
${ }^{1}$ It is important to note that, innovation or invention in his work are not restricted to technological ones, but are broadly conceived as changes observable in all aspects of society, from laws and languages to religions and politics.
} 
149): that is, the extent and specific ways in which subsequent inventions and change are influenced by imitative practices. Potentiality and uncertainty are crucial aspects of imitative rays in that how they form and proceed hinges on several possible ways in which imitative practices encounter one another. The precise trajectory of imitative rays is uncertain because it depends on whether imitations create convergence, divergence, interference or mutual cancellation. Therefore, the 'progress' of change can be indeterminate because such process might not be immediate and may materialise over great distance and intervals of time (Tarde, 1903, pp. 144-6). Further, progress in society, politically or technologically induced, can be ambiguous because it is achieved through experimentation involving diverse actors, ideas and practices. These experiments 'make and entertain all kinds of contradictory inventions and vagaries which appear first here and then there' until the point when 'the advent of some clear formula or some suitable mechanism ... serves thenceforward as the fixed basis for future improvements and developments' (Tarde, 1903, pp. 148-9).

Accordingly, similar to the notions that markets and economies are made rather presumed (Karppi \& Crawford, 2015; Knorr Cetina \& Bruegger, 2002; MacKenzie, 2004; McFall, 2011; Muniesa, Millo, \& Callon, 2007), smart cities emerge from the interplay between various imitative rays that share ideas, promote beliefs, motivate innovations and test them as products. For Tarde (2007; and also Lépinay, 2007), the results of the interplay, and therefore the development of smart cities, can be open-ended and uncertain. This is because imitative rays are situated in and progress through the participation in and cooperation with social, material and economic environments where particular problems arise and necessitate inventions (Barry, 2013).

Following Tarde to understand smart cities 'up close' and 'from the inside', we are therefore drawn to examine diverse ways in which passions are intertwined with economic life and urban change. For Tarde, the passions to reason, discover and invent feed into the degree and intensity of what can be repeated and improved again: 'The more people invent and discover, the more inventive and the more eager for new discoveries they grow'. Drawing upon Tarde to analyze smart cities further directs our attention towards the complex rationality and affect (e.g. desire and passions) that shape 'both the calculating and affective sides' of urban social and economic life (White quoted in Borch, 2007, pp. 550-1). Tarde resists 'rational individuals' or 'irrational crowds' as analytical units. Instead, he 
focuses on how imitative rays, which are enhanced by shared desires and passions, lead to particular patterns of exchange of information or economic transactions (Tarde, 2007).

Analysing smart cities through Tarde then means an exploration into how these cities emerge from the continuous (re-)production of subjectivities and economic operations. When individuals engage in economic activities, for example when financial market traders are in action, the market is shaped by and also shapes the specific ways that traders engage with the market (Karppi \& Crawford, 2015; Lange, 2016). Accordingly, subjectivity is 'neither prefixed nor stable, but is indeed a plastic entity that is formed and reformed in and by the economic engagement' (Borch, 2007, p. 562). Similarly, in the context of smart cities, it becomes important to address the affective charge that energizes 'urban imitations' and the mutual shaping of innovations, markets and economic life (Borch, 2005; also Thrift, 2004). This widespread and immediate imitation in urban social and economic life is the 'perfect and absolute' mode of sociality, consisting of 'intense concentration of urban life that as soon as a good idea arose in one mind it would be instantaneously transmitted to all minds throughout the city' (Tarde, 1962 in Borch, 2005, p. 70). That is, we can turn our attention towards how smart cities arise from 'passionate imitation' (Barry \& Thrift, 2007) as a machine for modern economic life and also a machine to intensify the interests for continuous innovation.

These passions, inventions and imitative radiations are still susceptible to capitalist operations, of profiting from propensities, despite the seemingly 'micro-' or individualist inclination. ${ }^{2}$ New markets are moulded with the assistance of technological and data-driven innovations that observe, detect, manipulate and capitalize on social, affective, psychological, gestural or neurological interactions through which one person becomes affected by another (Kerr, 2017; Thrift, 2008). While knowledge productions and innovations seek to exact the desires for and beliefs in the new markets, they also create ambiguity, precariousness, fragility and opaqueness in the complex interplay between differently involved individuals, agencies and techniques of operating the markets (Miele, 2011; see also Cockayne, 2016; Gill \& Pratt, 2008; Kerr, 2016; Ross, 2008). Drawing on these developments, a Tardean approach to smart cities requires shifting attention towards how entrepreneurial life and practices are 'temporary aggregates, partial stabilizations, nodes in networks' (Latour \& Lépinay, 2009, p. 9) that energize and also capitalize on the desires and beliefs in the smart economy, and the technique and practical arrangements to

\footnotetext{
${ }^{2}$ But see debates around nomadology and structure in, e.g., Candea (2010) and Tarde (2012).
} 
materialize and spread such passions (also Barry, 2013). For Latour and Lépinay, such contagion 'moves constantly, from point to point, from individual to individual, but without ever coming to a halt at any specific stop' (Latour \& Lépinay, 2009, pp. 9-10). As we will discuss below, such contagion is continually reworked and re-energizes the passions and practical arrangements for entrepreneurial life and cities to progress. Accordingly, the following sections examine the 'lengthening of networks' (Latour \& Lépinay, 2009, p. 61), which assembles individuals, events and smart cities and devise economic life and practices for the passionate interests for digital innovation through hackathons.

\section{Entrepreneurial life and digital innovations}

\section{Passions and professions}

Hackathons typically start on a Friday evening and end on a Sunday evening. There is often no set hours, with teams working late at night on Friday and Saturday, resuming early on Saturday and Sunday mornings. A typical schedule for a hackathon is summarized in Table 1. Hackathons can be simultaneously exciting, competitive, stressful, frustrating and fruitful. Participants have to develop a project idea, sometimes from scratch, map out its design and logic, build a prototype app or machine, identify its technological and market niche, present the economic values of the project succinctly, and learn to work with team mates that they might have no previous experience of knowing.

Table 1: Typical hackathon schedule

\begin{tabular}{|c|c|c|c|}
\hline & Friday & Saturday & Sunday \\
\hline Morning & $\begin{array}{l}\text { - Registered participants } \\
\text { preparing project ideas (not } \\
\text { mandatory) }\end{array}$ & $\begin{array}{l}\text { Start working on project: } \\
\text { clarifying ideas and specifying } \\
\text { technical requirements }\end{array}$ & $\begin{array}{l}\text { - Might have the final round of } \\
\text { mentors or workshops (e.g. } \\
\text { for presentation) }\end{array}$ \\
\hline Afternoon & $\begin{array}{l}\text { - Participants starting to arrive } \\
\text { and register for the event } \\
\text { around } 4-5 \mathrm{pm}\end{array}$ & $\begin{array}{l}\text { Organizers introducing } \\
\text { technical workshops and } \\
\text { mentors available for advice }\end{array}$ & $\begin{array}{l}\text { - Project development ends } \\
\text { around 3-5pm } \\
\text { - Teams preparing for project } \\
\text { presentation }\end{array}$ \\
\hline Evening & $\begin{array}{l}\text { - Introducing event sponsors } \\
\text { - Participants pitching ideas } \\
\text { - Forming teams and getting to } \\
\text { know team members } \\
\text { - Task allocation }\end{array}$ & $\begin{array}{l}\text { - Continue with project } \\
\text { development } \\
\text { - Working late, with some } \\
\text { events running on a } 24 \mathrm{hrs} \\
\text { basis }\end{array}$ & $\begin{array}{l}\text { - Project presentation and } \\
\text { result judging } \\
\text { - Networking throughout and } \\
\text { after the event }\end{array}$ \\
\hline
\end{tabular}


Furthermore, the skills possessed by team members and the team dynamics have immediate impact on the variety of projects that can be pursued during the weekend. Figure 1 below illustrates typically preferred skills for a hackathon, which mostly are technical capabilities. In addition, business, marketing and industry knowledge and capabilities are valued because they are important for providing relevant insights and marketing skills to the team throughout the weekend for convincing the judging panel of the values of the prototype. Meanwhile, the participants who are not considered technically 'competent' (perhaps possessing only an interest in participating or some level of domain expertise) are often largely ignored and those pursuing their own, rather than the project's, agenda are ignored or ejected (or their influences kept to a minimum). Interviewee SCH39 went a step further, doubting the legitimacy of domain experts or interested citizens in a hackathon focusing on improving the experiences of living in a smart city:

'it was kind of, I'd say it was really only relevant to maybe [the mentor] and yourself ... and I'd say no one else really gave a shit'

Accordingly, it is not surprising that domain experts or interested citizens fall out of the social imagination of hackathon organizers and are classified as 'Spectator' and their presence is limited to 'Friday \& Sunday ONLY'.

Figure 1: Preferable hackathon skill sets and indicative costs for entering a hackathon

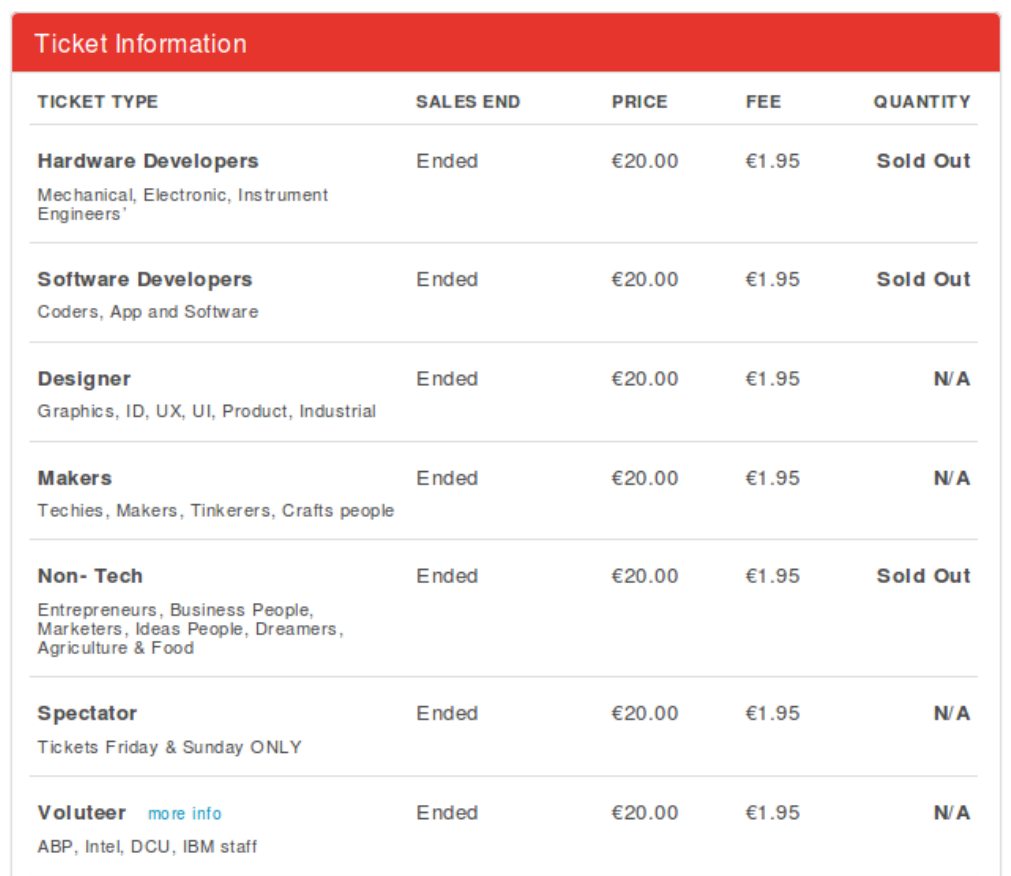


Nonetheless, participation in hackathons is growing as a social and cultural practice in smart cities. Hackathons build on the long-running passion for technology tinkering by 'makers', 'hackers' or 'expert amateurs' (Delgado, 2013; Kuznetsov \& Paulos, 2010; Toombs, Bardzell, \& Bardzell, 2014). The growing popularity of hackathons provides another venue for entertaining such passions and further appeals to a broad segment of people employed in the information technology sector, broadly defined. For Interviewee H33, the motivation to attend was 'just want to have fun', and for Interviewee H30 it was 'just to come along and build ... things, anything software related so just to hack for a weekend'. In pursuing the passions, a sense of 'community' grows between participants who 'don't have a specific interest in anything, except tech and maybe winning something' (Interviewee SCH39). Furthermore, in these hackathons, passions and professions are inseparable. Technology development is often part of the participants' everyday job and also a hobby and hackathons provide the participants an opportunity to chase the thrill of competing with one another to finish a project in a short timeframe:

'... technology is something I have been extremely interested in. I have often hacked with Raspberry Pi's, Arduino and I have done a lot of hardware hacking. My background is in information systems, so it kind of came together. And I thought great, if I can get with a group of guys who will put some thinking together and give 48 hours to creating something amazing, let's do it. So it was very much just I love tinkering around and wanted to create something.' (Interviewee H2)

For these participants, 'it is very hard to get in contact with people who are similar minded, who have the technical skills to go along with my business background' (Interviewee H22). As the interviewee commented, while deciding to participate is an individual's choice, once you are in the venue, participation becomes a social and collective endeavour:

'It is self-motivated, but once you are there it is less like having to make yourself sit down and do it, it is a bit of fun. It is kind of a community thing as well.' (Interviewee H3) 
Accordingly, the 'chance to work with friends', to 'really work together' as opposed to going talks, separates hackathons from other tech events, such as 'meetups' as a way of establishing and sustaining friendship. However, their motivations also attest to the argument that hackathons are for entertaining personal interests rather than as a means of pursuing social and ethical values or enacting alternative forms of citizenship (Irani, 2015; Lodato \& DiSalvo, 2016).

The exciting opportunity of combining passions and professions engenders new questions concerning current and future work. Hackathon participants can stay in touch with ongoing innovations and future trends in the industries they work in. As Interviewee H31 reflected, attending the events is a way of anticipating the technological future by exposing herself to ideas about 'how banking will work in 2020, so what new systems, new services, new technologies we can introduce to make it better for customers and for the bank as well'. However, contra to ideas of self-empowerment, concerns have been raised regarding hackathons, and other 'open innovation' schemes, as to their exploitation of labour and knowledge (Ettlinger, 2017; Gregg, 2015). Open innovation events such as hackathons provide a wealth of potential free ideas and investment opportunities to the organizers and sponsors. As Interviewee H37 noted, for companies and municipalities involved in sponsoring or co-hosting hackathons, they can look at the ideas and say that is very, very interesting, I didn't actually see that happening'. Alternatively, the event can be a 'recruitment drive' for multinational or start-up companies to look for new talents by observing how they perform under stress and work with others in a real team. As far as indigenous or niche markets are concerned, hosting hackathons 'is a listening tool[, ...] listening to what people want moving forward regarding innovation, developing new products' and 'what the market is telling us'. In addition, hosting tech and hacking events attract participants from Ireland and other parts of the world and 'booster' (Boyle, 1997) Dublin as a location and a brand for technological innovation on a global stage:

'... we have had participants from Sweden and Denmark, some of the Scandinavian countries, and Scotland and Italy coming to some of the hackathons at this stage. ... So it is a way of getting ourselves known internationally as well ... Having 250 people attending a hackathon the same weekend when there is two other hackathons happening just shows that Dublin as a location for innovation.' (Interviewee H37) 
Such exploitative practices occur with little resistance by participants in part due to the ongoing alienation of subjectivity and passions at work and the promise for future employment in a labour market that is already precarious and ambiguous. Particularly for programmers, because of the precariousness already in their employment (Kerr, 2016; Kerr \& Kelleher, 2015), they often develop 'pet projects' outside of work to keep up with new technologies, upgrade their skills, and reaffirm themselves as creative programmers. Hackathons thus provide a new pathway for the colonization of the passions of the programmers and the normalization of increasingly invasive and exhaustive work practices. Such colonization celebrates entrepreneurial life by ensuring that the upskilling occurs in employees' own time, at their own costs, and consuming their own passions:

'you know the way you have your list of "I should spend the evening programming" and you don't. So that was my idea, if I go along to this I will actually spend that amount of time.' (Interviewee H20)

Upskilling is important for this interviewee because, as an information system administrator, he undertakes very little code writing as part of his job. The division of labour in the IT, and related industries means that, despite 'working with computers', there is 'a world difference' from software development, where his passion really lies, and how he wants to develop his career:

'Well [as] sys[tem] admin, I go in, I download Java and I configure it to be installed on 80 computers. There is a small amount of development work in sys admin but it is very small, ... you might have to write 10 lines of code. ... I would say a single digit percent of my time is spent coding. I work in schools with teachers, so I might go in and the teacher would be like, I don't know how to burn a CD. So, it is not altogether technology enough. So, I might go in and teach teachers how to do things, whereas development is code all the way.' (Interviewee H20)

Similarly, some programmers cannot show the code they write or software they develop in their present employment to prospective future employers due to commercial sensitivity of the projects. Faced with these constraints, they appropriate hackathons as another means to demonstrate their technical competences: 
'... it is quite good to get extracurricular work, extracurricular code that you have worked on, like outside of my day to day job because I can't really show that code to anybody if I wanted to move on in the future or get a job or anything. ... So it is a nice way to actually go and do it and [show] you have done it.' (Interviewee H2)

Moreover, hackathons are a place to establish entrepreneurship, as Interviewee SCH39 commented on his motivation for participation: 'I'd like to be a tech entrepreneur as such'. Particularly useful in terms of participation is the opportunity to expand business networks. The flourishing opportunities at hackathons to network with representatives from major companies that sponsor the events, which would otherwise be difficult to establish, can draw intense interests from participants. For example, one of the participants we interviewed took part in a banking hackathon because it presented a great opportunity to pitch the business ideas that he had been developing to his new contacts:

'I ... would be around start-up events quite a bit. I love attending them. I had an idea to pitch and the fact that [bank name] was hosting it was an opportunity to talk to the bank, because sometimes it is hard to get meetings within the bank if you do have an idea that relates to them. So, they are really my motivations for going. (Interviewee H22)

In addition, hackathons can be appropriated for seeking new career opportunities. In the words of another participation, hackathons are another means 'to improve my networking and see if I get an opportunity to join another company'. For this particular participant, the strategies paid off 'because one week ago I wasn't working and I started working four or five days ago' (Interviewee H21).

Despite the passionate participation in hackathons, in our experiences of attending (and winning) hackathons, the prospect of any innovations beyond prototype stage is hampered most notably by financial constraints with respect to initial seed funding and subsequent investment thereafter. The potential pressure of existing work commitments coupled with social and cultural issues all work against the conceptualisation of a realistic business model. Moreover, the transience of the constellation of attendees also mitigates against the realistic production of any tangible product. Even with these constraints, the 
passionate, inventive and imitative practices to pursue digital innovations in the development of smart and experimental urbanism continue to lengthen. A clear example is the growing tendency to conduct government procurement practices through 'procurement by challenge' wherein cities seek novel ideas to urban issues that might be fast-tracked into prototyping and adoption (Coletta, Heaphy, \& Kitchin, 2017).

\section{Inventions and imitations}

Hackathon participants invent and imitate participation techniques to increase their chance of completing prototype development and earning prizes. The investment on developing these techniques turns hackathon participation and the passions for technology into another set of professional encounters and forms of work, albeit occurring during weekends and in a new space. Such work is organized without the usual formal management structure and leadership dictating roles, though those emerge in situ.

For the most part, these inventions and imitations are necessary because there are considerable uncertainty and precarity inherent in the process of team formation and successful completion of hackathons. A prototype as a project outcome depends on the right combination of interpersonal skills and technical competences. The teams need to recruit enough people, e.g. 5-6 team members, recruit enough skill sets that cover all aspects of project development (e.g. front and back-end developments, graphics, etc.) and form leadership that would help the teams navigate through the troubles the teams will encounter during the course of prototype development. It is not unusual that teams will face situations where they are short of people or talents. Often 'negotiation that goes on behind the scenes' becomes a test with teams 'react[ing] to different things and trying to swipe people from other teams'(quotes here and below, Interviewee H37). Alternatively, if a team is formed, but lacks of the leadership required to turn an idea into a project, 'the whole idea falls apart' and project members 'will jump ship to other teams'. Even if there is a prototype to present at the end of the event, it takes training and experiences to deliver the prototype ideas to the judging panel effectively.

However, developing hackathon techniques can be difficult and work practices cannot be readily replicated. Hackathons, as Interviewee H33 observed, 'are all different' and, as Interviewee H32 further pointed out, the differences can be due to hackathons having their own themes and attracting different kinds of participants. Also, participants can have their own attitudes, habits or skills, as well as having diverse expectations towards 
any given hackathon. Still, many participants seek to invent techniques when presented with such uncertainty and adversity. For some participants, whether 'you have a good idea ... is what matters' for ensuring successful hackathon results (Interviewee H21). They observed that a more polished idea can draw more attention during the initial pitch, but also found that the idea does not have to be fully developed. In addition, an attractive idea can encourage more participants to join a team and hence more technical capabilities for building the prototype. To pursue the tactics further, some other participants either learn to discern which ideas and teams to join, or organize a team themselves before a hackathon starts:

'Some people get there, they already have a team so they don't get there alone. ... [I]t is much easier because probably they have been working on the idea before. ... They maybe brainstorm before, so it would be easier to move on with the idea and build the project.' (Interviewee H21)

The tweaking of participation techniques does not stop at the end of a hackathon. Instead, participants reflect upon their experiences and devise other techniques for subsequent hackathons. For Interviewee H23, there will be more of an emphasis on actions rather than discussions and a more realistic goal for the project. The reorientation of hackathon strategies then concentrates on what is 'achievable during the weekend', which is likely 'to be something much smaller' so that the team can 'reduce the amount of discussion on what this thing could be and shrink it down'. The reflection, preparation and revision for hackathon participation are 'imitative techniques' that individual participants devise or acquire to increase the chance of winning, which compels more participants to follow suit to stay competitive in the events. The importance of these imitative techniques grows as participants take their participation more seriously, treating it as a weekend profession and calculating their 'return on investment'. Many hackathons ask for entry fees and there are potentially other costs, including accommodation for a weekend, travel and other expenses, which in turn adds to the intensifying determination for better results:

'... if I was going to Edinburgh I would need to ensure that I have a team before the hackathon ... . My mindset would be more about competition and winning. That is the main difference. ... [Otherwise,] you can just be relaxed and have fun. But if you 
need to make an investment you expect a return on the investment.' (Interviewee H31)

Crafting these techniques take an emotional toll on participants and affect the emotional charge and participation strategies in individual teams and across the events. For example, Interviewee H20 'started off lackadaisical and then kind of got into the flow of things', but was stunned by the intensity and devotion to prototyping. The level of competition that can accumulate at a hackathon took him by surprise: 'I was like, whoa, these guys spend a lot of money on this and really expect it to produce good stuff'. With this realization, he has worked to improve his tactics for future events. He will 'pitch the idea and say, I need a business guy, a designer and I need an iOS guy, come and join me, we are going to win. I am going to be serious from the beginning'.

Consequently, the more invested participants are regarding hackathon participation, emotionally or investment-wise, the more likely they are to seek control over prototype development. As participants acquire more intimate and practical knowledge about how hackathons are organized and how teams work (or fail), they leverage their participation experiences and insights to plan subsequent events. For Interviewee H30, hackathon participation stimulated ideas about how he could improve his tactics for participating by imitating others'. He would become 'more vocal' and engage more actively once he acquired the knowledge about the mechanics of hackathons, particularly in terms of the development of ideas and projects:

'But next time, because I know it is a bit of fun and everyone pitches ideas and they can be loose ideas, I might even take part in that. ... I would probably be a little bit more vocal and participating from the beginning. It took the first few hours to get comfortable with the environment but now that I know what to expect I would probably do a bit more.'

In other words, as hackathon participation techniques mature and become imitated, the 'fun' element, which was an initial motivation for some participants, can diminish, replaced by a more 'controlled' approach to prototype development. Prior preparation has ceased to be a matter of competing on a level playing field for Interviewee H22, but instead 
is to get a head start. He would exact the project idea and relevant details for a greater chance to enter an incubator programme and launch a start-up business:

'I will already have a team and I will be much more prepared. I will have the pitch ready and a draft outline of what I need to get done over the weekend. So, it will be a lot more controlled with an end purpose of hopefully getting incubation space because I have experience in the area and it could be a reality. That is the difference.'

\section{Programme and progress}

Hackathon organizers also seek invention and imitation but for fine-tuning hackathon programmes and space so as to ensure the teams progress well and provide a return on investment for the sponsoring companies. These arrangements do not specify direct and clearly defined outcomes. Instead, they engineer 'active spaces' as 'a means of harnessing and working with process in order to produce particular propensities' and intensify entrepreneurial governance practices (Thrift, 2008, p. 93; also Wiig \& Wyly, 2016).

Some arrangements conform to the conventions of event organisation: hiring venues in central locations and with easy public transportation for increasing participant numbers. Simultaneously, tweaks and inventions are carried out for increasing hackathon productivity. Engineering spaces for the fluid and intersecting flows of participants and information at hackathons is one such example. Hackathons start as a big crowd, for

introducing the events and sponsors, and also for participants to share ideas and get to know each other. They then become small group events after teams are formed, engaging in conversation and working on their projects (see Figure 2 for illustrations). At the same time, sponsors who provide equipment or have promotional stands have to be allocated with appropriate space for participants to reach them and seek advice when required. Before the small groups all re-congregate for the final stage of presenting project results and judging, there are intermittent workshops or mentor sessions where participants across the various projects gather to get advice from workshop leaders or mentors. 
Figure 2: hackathon crowds dispersed into small groups for projects (left) and gathered for event opening and conclusion pitches (right)
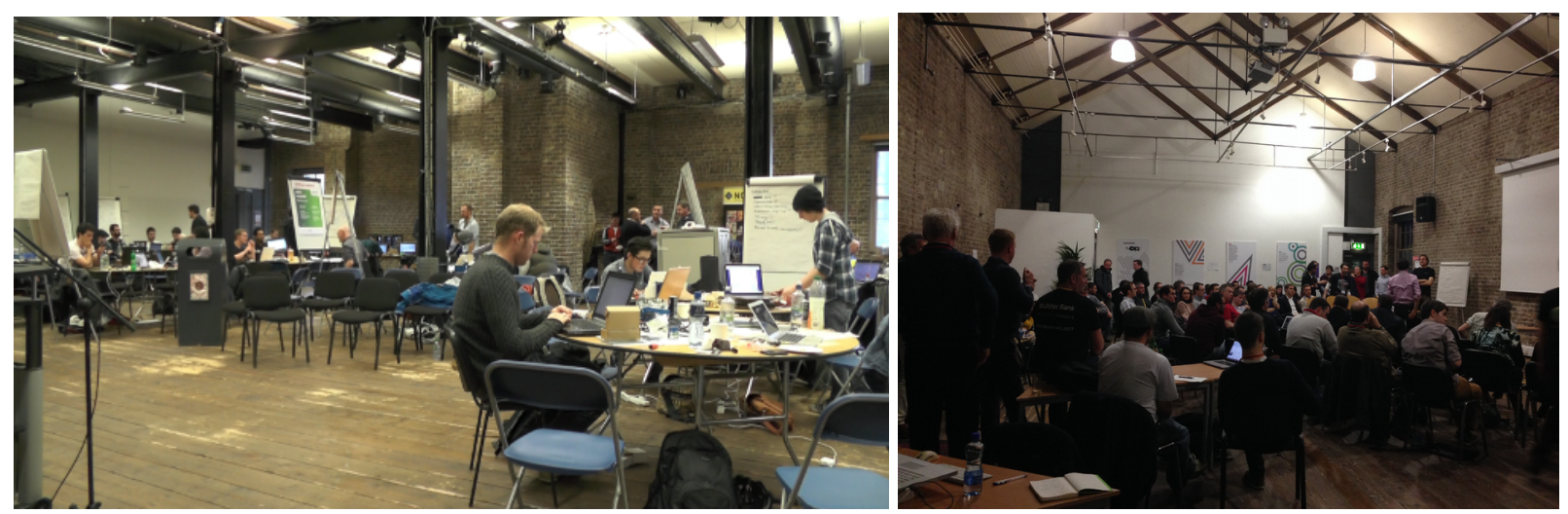

As noted during an interview with a hackathon organizer, the material and spatial arrangements for the events focus on making 'the building work to the schedule' for bringing about participants' collective creativity, rather than asking them to adapt to the venue's constraints. Explaining in more detail, the organizer (Interviewee H37) went through different aspects they had considered during the development of a dedicated floor for hackathons:

'where people enter, registration, where we serve the food, where would the main teams go to when they actually sit down when the teams are formed and get into developing the idea. ... And I suppose that is where we came out with the layout ... so it is a flow, if that makes sense, and it is the design with that flow in mind.'

Creating the 'flow', the organizer and his team developed 'the idea of just stripping the floor out ... and just leaving it in that raw state with no carpets or whatever', for 'giving people that freedom to do what they need to do' during the events (see Figure 3 below). There is also a slight twist to the flow in the space by intentionally having some space that is closed off from the main hackathon area. This is to allow participants to have productive breaks outside the main hackathon area:

'I think the format of having multiple different rooms where people could come and go and break out for chats with mentors, to take time out to go for a coffee, I think the agenda allows for the intense debate and working on ideas, but it also facilitates time out as well.' (Interviewee H19) 
Figure 3: Dedicated hackathon floor and space design
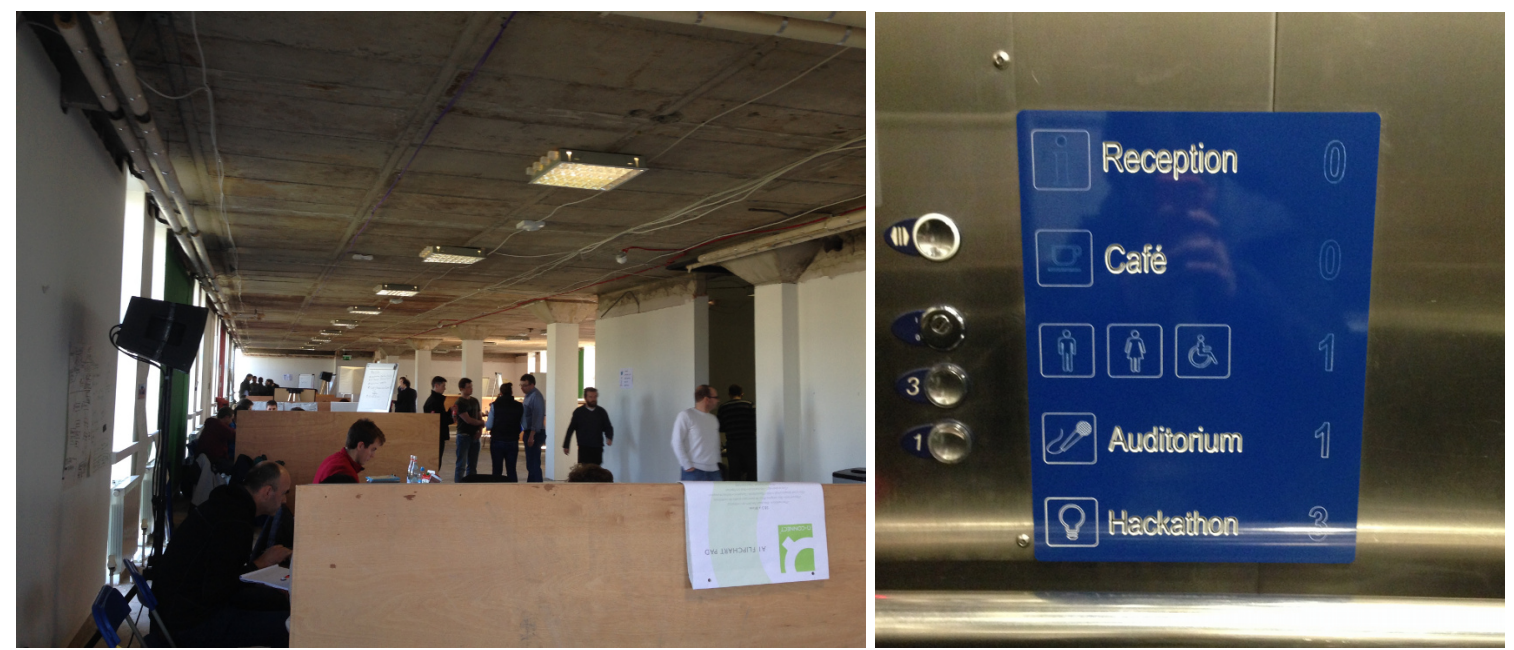

At the same time, while facilitating the flow of creativity, 'you don't want people spread out all over the place', as Interviewee H37 commented on another aspect of arranging hackathon space. This has to be balanced with other considerations, such as: 'people don't feel they are breathing down each other's necks with the teams and people listening in and things like that'. Therefore, for example, the space available for a particular hackathon has to be adjusted according to participant numbers so that participants are in a tight enough area where there is a buzz created'. Other arrangements that have been experimented, and considered as successful, include furniture (e.g. adding couches and coffee tables as informal meeting area at a smaller hackathon), the placement of food areas or setting up a dedicated space for sponsors for their own activities, such as informal interviews. These design considerations and space configurations are a means of space engineering for harnessing creativity and producing a 'culture of innovation'.

The design of hackathon programmes is another important aspect of engineering the event to increase productivity. Such tweaking of hackathon programmes, as Interviewee H37 commented, 'doesn't stop, it never stops' and 'it is constantly evolving and experimenting'. While most hackathon schedules conform to the pattern outlined earlier, tweaks to the schedules are carried out according to the theme of a hackathon or where it is hosted. For a hackathon sponsored by an Irish bank, the bank brought in a consultancy and financial technology company to help run it. The bank took on board the programme format suggested by the company because the people in the company 'have been through a number of these, they know what works, they know what hasn't worked in the past' 
(Interviewee H19). But for the bank, 'it was good to have something that was Irish, something that was recognisably different from the hack in London'. Accordingly, local adjustments were made, including whiskey tasting and an emphasis on interactions rather than simply focusing on coding:

'if you look at the amount of time that is put aside for pure hacking, it is only about $50 \%$ of the agenda. ... the agenda allows for the intense debate and working on ideas but it also facilitates time out as well. ... If you moved from $50 \%$ coding to 70 or $80 \%$, I think people would just get bored and burn out.' (Interviewee H19)

However, the labour invested in inventing and imitating measures for ensuring progress also attests to the uncertainty around quick prototyping at hackathons. Sponsors are also implicated by the uncertainty and therefore other measures had to be implemented for hackathons to be worth the investment. For the sponsors, the value of sponsoring the events does not rest solely on the prototypes and the ideas behind them and can instead derive from their involvement in 'technical workshops'. These workshops are opportunities for sponsors or hackathon organizers to promote their products where participants could be introduced to their new data analytics platforms, new hardware to build Internet-of-Things devices or new tools for accessing data from particular sources to create new services. Alternatively, for hardware manufacturers, they can have stands that are staffed throughout the weekend to provide technical assistance to participants who encounter problems with the hardware. Such assistance becomes valuable feedback for these companies to improve their products and manuals subsequently to ensure easier and wider adoption of their products.

\section{Conclusion}

From passions for tinkering to uncertainty in prototyping, we have analysed the passionate participation and production of hackathons and entrepreneurial life in smart cities.

Hackathon participants, organizers and sponsors use the events as opportunities to pursue their passions for digital innovations and entrepreneurial life. The practices of participating and organising hackathons are both inventive and imitative and seek to create greater chances for producing better prototypes at the close of the events, individually for the 
teams and collectively for the hackathon organizers. Participation in hackathons raises the hopes of acquiring more skills, greater access to business networks, a sharper sense of potential innovation and more knowledge about future markets. These are all necessary ingredients for better career trajectories, further development of prototypes, attracting investment to fund the development and ultimately establishing start-up companies. These practices therefore lengthen passions for digital innovation and also entrepreneurial life.

However, our analysis also illustrates that precarity, ambiguity and uncertainty plague programmers and prototypes alike and are engineered into the development of entrepreneurial life and smart urbanism. Upskilling becomes outsourced to these tech events and does not guarantee career advancement. The lifespan of prototypes is contingent upon the success at hackathons, which in turn relies on the opportunity of forming a team with an appropriate skill set, collaborative ethos, and leadership. Furthermore, the pressure to succeed compels participants to focus on developing participation techniques and to extend the control and management of prototyping processes. Hackathon participation thus becomes a profession in its own right, demanding both material and immaterial investments in the forms of time, money, physical presence and continued preparation for, and improvement, on participation. The professionalization of participation thus becomes exploitative in two ways. There is the increasing outsourcing of professional development and the demand of personal investments, and also appropriation of the enjoyment of technology tinkering (those who attend to have fun) for personal professional interests (those attend to win).

More importantly, we suggest passion and imitation as an analytical lens for subsequent examination of economic and entrepreneurial life, and also digital innovation and smart urbanism. We demonstrate how the approach ventures 'up close' and into 'the inside' but also remains sensitive towards to neoliberalizing and exploitative operations of hackathons. Such an approach follows the processes whereby passions become diversified, intensified, affected and changed because they come into contact with one another. The interactions among different passionate actors also lead to uncertainties and unanticipated practices, logic, visions and relations emerging when they are imitated. An example of such unanticipated imitative rays is the convergence of the passions of programmers and organizers but with the result of the lingering uncertainty and precarity of prototype's future. On a city scale, hackathons are appropriated for growing the digital economy and city branding and lead to exhilarating but precarious entrepreneurial life in smart cities. 
In our case study, we focused on the passions and imitations as socioeconomic practices, whether carried out by individuals, government agencies or multinational corporations, that energized digital innovations and smart urbanism. However, there are many other unfolding socioeconomic practices and initiatives that could leverage the lens of passionate and imitative practices to examine the precarious and ambiguous futures of individuals, prototypes, proof-of-concepts, open innovation schemes, innovation districts, governance processes and government restructuring in the pursuit of smart urbanism. Such research can yield further insights into how the pursuits of digital, entrepreneurial and smart cities generate their own precarity, ambiguity and uncertainty while adopting open, transparent and collaborative logics and practices.

\section{Acknowledgement}

Over the long course of developing the research and the paper, we have benefited from many critical but encouraging comments by present and previous members of the Programmable City project, as well as colleagues in Maynooth University, especially Aphra Kerr, Kylie Jarrett, Mary Gilmartin and Mark Boyle. The research is funded by a European Research Council Advanced Investigator award (ERC-2012-AdG-323636-SOFTCITY).

\section{References}

Barry, A. (2013). Material Politics: Disputes along the Pipeline. Oxford: Wiley Blackwell.

Barry, A., \& Thrift, N. (2007). Gabriel Tarde: Imitation, invention and economy. Economy and Society, 36(4), 509-525.

Borch, C. (2005). Urban imitations: Tarde's sociology revisited. Theory, Culture \& Society, 22(3), 81-100.

Borch, C. (2007). Crowds and economic life: Bringing an old figure back in. Economy and Society, 36(4), 549-573.

Boyle, M. (1997). Civic boosterism in the politics of local economic development:'Institutional Positions' and 'Strategic Orientations' in the consumption of hallmark events. Environment and Planning A, 29(11), 1975-1997. 
Candea, M. (Ed.). (2010). The Social after Gabriel Tarde: Debates and Assessments. London and New York: Routledge.

Cockayne, D. G. (2016). Entrepreneurial affect: Attachment to work practice in San Francisco's digital media sector. Environment and Planning D: Society and Space, $34(3), 456-473$.

Coletta, C., Heaphy, L., \& Kitchin, R. (2017). Accidental smar urbanism: Smart Dublin and the shaping of Dublin as an accidental smart city. Programmable City Working Paper.

Datta, A. (2015). New urban utopias of postcolonial India: 'Entrepreneurial urbanization' in Dholera smart city, Gujarat. Dialogues in Human Geography, 5(1), 3-22.

David, P. A., \& Foray, D. (2002). An introduction to the economy of the knowledge society. International Social Science Journal, 54(171), 9-23.

Delgado, A. (2013). DIYbio: Making things and making futures. Futures, 48, 65-73.

Ettlinger, N. (2017). Open innovation and its discontents. Geoforum, 80, 61-71.

Evans, J., \& Karvonen, A. (2014). 'Give me a laboratory and I will lower your carbon footprint!' - Urban laboratories and the governance of low-carbon futures. International Journal of Urban and Regional Research, 38(2), 413-430.

Gibson, C., \& Klocker, N. (2005). The 'cultural turn' in Australian regional economic development discourse: Neoliberalising creativity? Geographical Research, 43(1), 93-102.

Gill, R., \& Pratt, A. (2008). In the social factory? Immaterial labour, precariousness and cultural work. Theory, Culture \& Society, 25(7-8), 1-30.

Government of Ireland. (2008). Building Ireland's smart economy: A framework for sustainable economic renewal. Dublin: Department of the Taoiseach.

Gregg, M. (2015). Hack for good: Speculative labour, app development and the burden of austerity. The Fibreculture Journal, (25), 185-202.

Heaphy, L., \& Pétercsák, R. (2016). Building smart city partnerships in the 'Silicon Docks' (pp. 208-221). Presented at the Creating Smart Cities: Collaboration, Citizenship and Governance, Maynooth, Ireland: Myanooth University. Retrieved from https://vimeo.com/184523994

Hollands, R. G. (2008). Will the real smart city please stand up? City, 12(3), 303-320. Irani, L. (2015). Hackathons and the making of entrepreneurial citizenship. Science, Technology, \& Human Values, 40(5), 799-824. 
Jessop, B. (1997). The entrepreneurial city: Re-imagining localities, redesigning economic governance or restructuring capital. In N. Jewson \& S. MacGregor (Eds.), Realising Cities: New Spatial Divisions and Social Transformation (pp. 28-41). Londno: Routledge.

Karppi, T., \& Crawford, K. (2015). Social media, financial algorithms and the hack crash. Theory, Culture \& Society, 0263276415583139.

Karvonen, A., \& van Heur, B. (2014). Urban laboratories: Experiments in reworking cities. International Journal of Urban and Regional Research, 38(2), 379-392.

Kerr, A. (2016). Recruitment, work, and identity in community management: Passion, precarity, and play. In J. Webster \& K. Randle (Eds.), Virtual Workers and the Global Labour Market (pp. 117-135). London: Palgrave Macmillan.

Kerr, A. (2017). Global Games: Production in the Digital Game Industry. NY: Routledge.

Kerr, A., \& Kelleher, J. D. (2015). The recruitment of passion and community in the service of capital: Community managers in the digital games industry. Critical Studies in Media Communication, 32(3), 177-192.

Kitchin, R. (2015). Making sense of smart cities: Addressing present shortcomings. Cambridge Journal of Regions, Economy and Society, 131-6.

Kitchin, R., Coletta, C., Evans, L., Heaphy, L., \& Mac Donncha, D. (2017). Smart cities, urban technocrats, epistemic communities and advocacy coalitions. The Programmable City Working Paper 26. Retrieved from https://osf.io/preprints/socarxiv/rxk4r

Knorr Cetina, K., \& Bruegger, U. (2002). Trader's engagement with markets: A postsocial relationship. Theory, Culture and Society, 19(5/6), 161-85.

Kuznetsov, S., \& Paulos, E. (2010). Rise of the expert amateur: DIY projects, communities, and cultures. In Proceedings of the 6th Nordic Conference on Human-Computer Interaction: Extending Boundaries (pp. 295-304). NY: ACM.

Lange, A.-C. (2016). Organizational ignorance: An ethnographic study of high-frequency trading. Economy and Society, 45(2), 230-250.

Latour, B., \& Lépinay, V. A. (2009). The Science of Passionate Interests: An Introduction to Gabriel Tarde's Economic Anthropology. Chicago: Prickly Paradigm Press.

Lauermann, J. (2016). Municipal statecraft: Revisiting the geographies of the entrepreneurial city. Progress in Human Geography, 0309132516673240.

Lépinay, V.-A. (2007). Economy of the germ: captial, accumulation and vibration. Economy and Society, 36(4), 526-548. 
Lodato, T. J., \& DiSalvo, C. (2016). Issue-oriented hackathons as material participation. New Media \& Society, 18(4), 539-557.

Maalsen, S., \& Perng, S.-Y. (2016). Encountering the city at hacking events. In R. Kitchin \& S.Y. Perng (Eds.), Code and the City. London and NY: Routledge.

MacKenzie, D. (2004). Social connectivities in global financial markets. Environment and Planning D: Society and Space, 22, 83-101.

Mansfield, E. (1968). The Economics of Technological Change. NY: Norton.

Marvin, S., Luque-Ayala, A., \& McFarlane, C. (Eds.). (2016). Smart Urbanism: Utopian Vision or False Dawn. NY: Routledge.

McFall, L. (2011). A 'good, average man': Calculation and the limits of statistics in enrolling insurance customers. The Sociological Review, 59(4), 661-684.

McFarlane, C. (2012). The entrepreneurial slum: Civil society, mobility and the coproduction of urban development. Urban Studies, 49(13), 2795-2816.

Miele, M. (2011). The taste of happiness: Free-range chicken. Environment and Planning A, 43(9), 2076-2090.

Muniesa, F., Millo, Y., \& Callon, M. (2007). An introduction to market devices. The Sociological Review, 55, 1-12.

OpenBSD (n.d.) 'Hackathons', OpenBSD, available from http://www.openbsd.org/hackathons.html, [accessed 19 March 2015].

Raco, M. (2012). A growth agenda without growth: English spatial policy, sustainable communities, and the death of the neo-liberal project? GeoJournal, 77(2), 153-165.

Ross, A. (2008). The new Geography of work: Power to the precarious? Theory, Culture \& Society, 25(7-8), 31-49.

Sabatier, P., \& Jenkins-Smith, H. C. (Eds.). (1993). Policy Change and Learning: An Advocacy Coalition Approach. Boulder, CO: Westview Press.

Scott, A. J. (2006). Entrepreneurship, innovation and industrial development: Geography and the creative field revisited. Small Business Economics, 26(1), 1-24.

Shelton, T., Zook, M., \& Wiig, A. (2015). The 'actually existing smart city'. Cambridge Journal of Regions, Economy and Society, 8(1), 13-25.

Tarde, G. (1903). The Laws of Imitation. New York: HHolt and company.

Tarde, G. (2007). Economic psychology. Economy and Society, 36(4), 614-643.

Tarde, G. (2012). Monadology and Sociology. (T. Lorenc, Trans.). Melbourne: re.press. 
Thrift, N. (2004). Intensities of feeling: Towards a spatial politics of affect. Geografiska Annaler, 86B(1), 57-78.

Thrift, N. (2008). Pass it on: Towards a political economy of propensity. Emotion, Space and Society, 1(2), 83-96.

Toombs, A., Bardzell, S., \& Bardzell, J. (2014). Becoming makers: Hackerspace member habits, values, and identities. The Journal of Peer Production, (5). Retrieved from http://peerproduction.net/issues/issue-5-shared-machine-shops/peer-reviewedarticles/becoming-makers-hackerspace-member-habits-values-and-identities/

Vanolo, A. (2013). Smartmentality: The smart city as disciplinary strategy. Urban Studies, 51(5), 883-898.

Ward, K. (2006). 'Policies in motion', urban management and state restructuring: The translocal expansion of business improvement districts. International Journal of Urban and Regional Research, 30(1), 54-75.

Wiig, A. (2015). IBM's smart city as techno-utopian policy mobility. City, 19(2-3), 258-273.

Wiig, A., \& Wyly, E. (2016). Introduction: Thinking through the politics of the smart city. Urban Geography, 37(4), 485-493.

Wyly, E. (2013). The city of cognitive-cultural capitalism. City, 17(3), 387-394. 